\title{
Ortín Montero, F. J. (2009). Los padres y el deporte de sus hijos. Madrid: Pirámide. 135 pp.
}

De acuerdo con Aristóteles, los hábitos buenos adquiridos en la juventud son los que marcan la diferencia. Debemos considerar el deporte que destaque el esfuerzo, el trabajo responsable, el espíritu de superación, la búsqueda de soluciones, la aceptación de unas reglas, el respecto, la observancia a la autoridad, el sentimiento de forma parte y de integración en un equipo y, el aprendizaje de aceptar la derrota y el fracaso.

Siguiendo esta línea, el libro que presentamos, forma parte de la colección "Guías para padres y madres". Su autor, Francisco José Ortín Montero, establece dos objetivos fundamentales en él, por un lado, pretende asesorar a los padres y madres de deportistas jóvenes sobre algunas de las claves que estimulan el disfrute o el sufrimiento en práctica deportiva. Por otro lado, presenta de forma estructurada el conocimiento del deporte. Así, los nueve capítulos que componen en el libro ofrecen una información de utilidad para entender mejor a los deportistas.

Respecto a la estructura de la obra, el autor introduce cada capítulo con una reflexión de una persona relacionada el ámbito deportivo. En este sentido, se pueden conocer de primera mano la opinión de deportistas de élite, entrenadores y psicólogos en relación a los temas que se tratan en él.

En efecto, José Joaquín Rojas Gil, inicia su reflexión sobre los valores que aporta la práctica del ciclismo y cómo su influencia en los menores que lo practican beneficia sus relaciones sociales y sus conductas. Observamos como entre los beneficios que se destacan, según Ortín, encontramos un aumento de la autoestima, mayor capacidad en la toma de decisiones, la adquisición de responsabilidades, la consecución de metas con esfuerzo y no de inmediato, mayor sociabilidad y sobre todo la adquisición de hábitos saludables.

Por otro lado, el autor se apoya en reconocidos investigadores en el ámbito del deporte y ofrece sus aportaciones como guía y ayuda a los padres y a los propios deportistas. Así, encontramos las tareas que proponen Crespo y Miley (1999) para conseguir la autonomía y una actitud responsable en los deportistas según las edades de los mismos con o sin la presencia del entrenador. Entre las interesantes fábulas japonesas, hay una que se relaciona con el objetivo que nos ocupa y es que hay que dejar que un niño se caiga, porque cuantas más veces se levante, más valorará el esfuerzo que ha hecho. En este sentido, el autor señala la delgada línea 
que separa la motivación de la presión. Así, debemos tener en cuenta que no es fácil mantener un equilibrio entre ambas ya que la motivación por realizar acciones no siempre está determinada por aspectos positivos. La manera de motivar a los deportistas es simplemente siendo un modelo positivo en la forma de enfocar las cosas y plantear los objetivos a conseguir. En efecto, la orientación debe realizarse para conseguir metas positivas y no tanto hacia evitar consecuencias negativas. De este modo hablamos de motivación intrínseca cuando está regulada por el propio deportista, siendo ésta más estable y duradera que cuando la motivación es extrínseca ya que solo le interesa las recompensas externas y cuando éstas se hacen difíciles de conseguir se pierde el interés y muchas veces se produce el abandono del deporte.

Uno de los paradigmas en Psicología es que hay conductas de las personas que se repiten o no en función, sobre todo, de las consecuencias que reciben. A este respecto, el autor destaca como se puede intervenir tanto en las situaciones que anteceden a la conducta como en las consecuencias concretas que se dan después de ésta. No obstante, se observa un mayor interés en variar las consecuencias que en modificar lo que ocurre antes que se dé el comportamiento, dado que esto último es más complejo de controlar.

En la última década, las investigaciones en Psicología señalan más efectividad cuando se aplican refuerzos positivos que cuando se dan refuerzos negativos o castigo para obtener conductas adecuadas. En el deporte es muy importante la selección precisa del comportamiento que queremos reforzar. Por otro lado, cuando se utiliza el castigo nunca se debe atacar directamente a la persona ya que podemos dañar aspectos psicológicos como la autoestima.

Es evidente que la obra de Ortín está muy bien fundamentada en los principios de la Psicología del Deporte, especialidad que en las últimas décadas ha experimentado un gran avance en el campo de la investigación y la aplicación. Desde 1990 hasta el presente, esta disciplina ha tenido una clara evolución de un tipo de trabajos descriptivos de la personalidad de los deportistas a una investigación más aplicada que intenta mejorar el entrenamiento psicológico y el rendimiento de los deportistas. Esto ha supuesto un considerable aumento en las publicaciones de autores de todo el mundo centrándose en áreas específicas básicas, psicobiológicas, psicosociales y educativas.

Ortín propone de forma eficaz el desarrollo del trabajo por objetivos definiéndolos correctamente y diseñando una planificación cuidadosa para alcanzarlos como clave del éxito deportivo. En este sentido, se incluye la metodología de la evaluación en todas las situaciones posibles para hacer un seguimiento de las mejoras alcanzadas y sobre todo para plantear alternativas en las dificultades encontradas.

$\mathbf{M}^{\mathbf{a}}$ del Carmen Pérez Ramírez, profesora titular de universidad, Departamento de Pedagogía de la Universidad Rovira i Virgili. 